\title{
Jornalismo feminino luso-brasileiro: notas de um diálogo
}

\author{
Paula Renata Luca Collares Ramis \\ Universidade Federal de Pelotas \\ Rosa Cristina Hood Gautério \\ Fundação Universidade Federal de Rio Grande
}

\begin{abstract}
Resumo
Partindo de proposições dos estudos culturais de gênero, este ensaio se propõe trazer um pequeno corpus de jornais publicados por mulheres brasileiras e portuguesas oitocentistas. A pesquisa volta-se para as representações das relações de gênero na imprensa, como diálogos ocorridos entre as feministas que adquiriram maior visibilidade em um momento histórico do feminismo que vem se construindo historicamente.
\end{abstract}

Palavras-chave: gênero; jornalismo; estudos culturais.

\section{Résumé}

A partir de propositions d'études culturelles du genre, cet essai propose d'apporter un petit corpus de journaux publiés par des femmes brésiliennes et portugaises du XIXe siècle. La recherche se concentre sur les représentations des relations de genre dans la presse, en tant que dialogues entre féministes qui ont acquis une plus grande visibilité dans un moment historique du féminisme construit historiquement.

Mots-clés: genre; journalisme; études culturelle.

Recebido em: 27/07/19

Aprovado em: 16/11/19

A palavra feminismo é utilizada para designar um amplo movimento histórico. Neste, todas as mulheres tiveram suas áreas de atuação, fossem elas quitandeiras, lavadeiras ou cozinheiras, consciente ou inconscientemente. As mais progressistas e alfabetizadas buscavam estabelecer alianças entre si por meio da atividade escrita e, por vezes, pelos contatos pessoais. Entre eles, os poemas, os romances e as cartas traziam em sua autoria a desejada emancipação. Mas foram nos jornais que as intelectuais consignaram maior êxito. Cá no Brasil ou lá em Portugal, as mulheres tornaram-se empreendedoras e utilizaram seus próprios jornais como estratégia de luta. Notadamente, formou-se uma rede de apoio das ações feministas entre os dois países fortemente amparada pelos nomes relevantes da lisboeta Ana de Castro Osório e as gaúchas Andradina de Oliveira e as irmãs Revocata e Julieta de Melo Monteiro. 
Resgatar a história do jornalismo exercido pelas mulheres é procurar entender a vinculação das jornalistas com o pensamento feminista do seu tempo. É entender como as ideias dialogaram com comunidades amplas no seio de uma sociedade essencialmente conservadora.

Neste contexto, tomamos o jornal como fonte primária de pesquisa e buscamos destacar a substancialidade de significados da história em relação ao "mundo feminino" e à história das mulheres. Em verdade, tornar-se-ia difícil entender o lugar social conquistado por elas no século XIX e XX sem transitar pelas páginas do jornalismo. Mauro Póvoas afirma que "os periódicos são fontes referenciais para pesquisas de vários tipos, sobretudo por documentar o passado por meio de textos — literários ou não — , de publicidade ou de retratos que evocam, em seu conjunto, de imediato o quadro histórico em que se pretende transitar" (2005, p. 12).

No início do século XX, tanto no Brasil como em Portugal, tem-se uma imprensa frequentada por mulheres, ou melhor, uma produção exclusiva das mulheres. O discurso que predominava nos periódicos era o de uma orientação educacional mais moderna para "o sexo feminino", como costumavam dizer. Entretanto, valer-se dos jornais como ferramenta de mudança social implicaria custos, mas as leitoras transformaram-se em assinantes, que movimentaram a circulação das ideias. Desta forma, as campanhas pela emancipação moral, advinda pela educação, ajudavam a criação de uma rede de organização de associações feministas que, por sua vez, tinham as assinantes também como membros. O número de jornais crescia e intensificava seu público.

Rodrigues (1998) escreve que o período de afirmação da imprensa naquele país deu-se entre os anos de 1836 a 1840, porém haveria de passar ainda algum tempo até que as mulheres assumissem as redações dos jornais. Enquanto esse momento não acontecia, O Correio das Modas, lançado em Lisboa em 1807, "parece ter sido a primeira folha especialmente dedicada às mulheres" (1998, p. 160). Depois, “O periódico sem política, dedicado às senhoras portuguesas, conta de um prospecto e sete números saídos em Lisboa (1998, p. 161). Mas Lisboa tornava-se um centro intelectual e as mulheres precisavam do seu próprio meio de informação; os periódicos eram o caminho. Elas assumiram as redações e, então, surgiram os jornais A Voz Feminina, publicado no ano de 1868, e seu coetâneo Ilustração Feminina; a Revista Sociedade Futura em 1902, e, por ordem cronológica, A Madrugada que teve publicações a partir de 1911, embora utilizamos, nesse texto, somente edições elencadas a partir de 1912. Todos publicados em Lisboa.

A Voz Feminina: jornal semanal, científico, literário e noticioso era composto por quatro páginas, tendo como redatores Guilherme T. Wood e Francisca Wood. O jornal que era "recebia colaborações exclusivas de senhoras", conforme estampava, passou a se chamar sugestivamente de $O$ Progresso em seu segundo ano de circulação. Sugestivamente, porque a partir de análise em um grande número de edições, todos versam sobre a necessidade de progresso, criticando a sociedade. Lê-se um excerto de 5 de janeiro de 1868 : 
Bem-vindo seja ano novo de 1868, bem-vindo sejas a este pitoresco e lindo Portugal [...]. Mas nós as mulheres, quero dizer as Exm ${ }^{\mathrm{a}} \mathrm{s}$ senhoras, que fazemos [...] encurtar vestidos, alongar vestidos, nesgar vestidos, [...] não há para nós outra carreira? Estes jovens tão instruídos, tão ilustrados, tão estudiosos de quem tanto admiramos os bigodes negros e reluzentes, que pensarão de nós? [...] não queríamos por mais tempo ser, o que até agora temos sido - bonecas! (ano I, $\mathrm{n}^{\mathrm{o}}$ 1, p. 1-2).

Em seu quarto número, o jornal muda o subtítulo para "Jornal semanal, dedicado à ilustração das senhoras", motivando novas conquistas, enquanto zombava dos velhos conceitos sociais, conforme se lê no recorte supracitado: "não queríamos por mais tempo ser, o que até agora temos sido: bonecas!".

A Ilustração Feminina: semanário de ilustração e recreio apresentava a seção intitulada "Moda", com noções sobre o "Império elegante". Já "Crônica Teatral" versava sobre os movimentos do teatro na cidade; e a coluna "Folhetins" trazia a literatura dos "grandes mestres". Entretanto, o periódico também trazia temas que questionavam certos preceitos sociais, como é o exemplo do texto "A mulher":

Os falsos preconceitos antropológicos que lhe negavam a capacidade intelectual desapareceram e as opiniões controversas que ainda hoje se levantam não tardam a aniquilar-se por falta de argumentos e confundidas pela justiça e pala verdade. [...] por que é que sendo a História a luz da vida não projeta nesta questão de alta importância sociológica mais que as trevas e amalgama da inquietude? (ano I, n [s.n.], p. 2, 17 de ago. 1868.)

Restava um sentimento de inquietude? De certo, pois a herança histórica dos preconceitos sobre gênero buscava na ciência a interpretação do servilismo.

A Sociedade Futura, que estava ligado à associação de mesmo nome, ${ }^{1}$ Revista quinzenal de educação, literatura e ciência era dirigida por Ana de Castro Osório e Olga Morais Sarmento. ${ }^{2}$ Teve suas publicações iniciadas em $1 .^{\circ}$ de maio de 1902 , contendo sete folhas. Entretanto, a partir do número 8, quando a revista fica sob direção de Olga Sarmento, passa a reduzir seu número de páginas para quatro e apresenta também colaborações masculinas, público que pretendia recrutar para as campanhas. O jornal fomentava uma educação feminina voltada para a manutenção da harmonia dos lares, uma vez que a emancipação moral se voltava,

\footnotetext{
${ }^{1}$ Muitos dos periódicos femininos estavam associados à criação de uma associação de mesmo nome, no caso, este, associado à Sociedade Futura, que primava por ações pela melhoria da educação e dos direitos civis das mulheres. Segundo a investigadora Isabel Lousada (2010), a revista teve edições entre 1902 a 1904.

${ }^{2}$ Segundo o Dicionário de escritoras portuguesas (2009), Maria Olga de Moraes Sarmento da Silveira nasceu em 1881 e era natural de Setúbal, Portugal, e faleceu em 1948. Poetisa, ensaísta e oradora, fez conferências em diversos países da Europa e América do Sul. Diretora durante muitos anos da Sociedade Futura, publicou vários livros, entre os quais O problema feminista, em 1905.
} 
necessariamente, para o desempenho do papel de mãe educadora. Em razão desse discurso, Castro Osório assina o texto "A mulher de há trinta anos e a mulher de hoje" e advoga que as mulheres devem renunciar ao excesso de literatura romântica e permutar para a ciência. Lê-se

\section{A MULHER DE HÁ TRINTA ANOS E A MULHER DE HOJE}

A época do romantismo agudo avulta a nossos olhos a turba desgrenhada das jovens que recitavam piano com os olhos em alvo, que dormiam de colete para adelgarem a cinta, defumavam o rosto para obterem a palidez interessante que a moda proclamava, numa eterna vida de romance. [...]. Essas eram as exageradas de todas as escolas, as desvairadas de todos os tempos; mas ao lado delas, as sãs, as ajuizadas, que liam os mesmos livros e conheciam as mesmas poesias não se deixavam levar em excessos de romantismo piegas. [...]. Isso no tempo em que a mulher não tinha, como a de hoje, em cada canto uma professora de primeiras letras na educação, por essas províncias fora um luxo. [...], quer dizer que a mulher, há trinta ou quarenta anos, conhecia e compreendia os escritores do seu país. [...] Como poderão sair, de crianças educadas assim, as mulheres que a sociedade reclama, fortes nas consciências dos seus deveres, que ao lado do homem seja companheiras e amigas, auxílio e guia nas horas negras da vida, iniciadora e educadoras dos filhos [...] (ano I, n. 1, p. 6, 1902).

O discurso permeia a ideia de uma educação que vai ao encontro do aspecto social humano em benefício de uma "verdadeira instrução", conforme supracitado, colocando as mulheres como cidadãs que tomam consciência de suas próprias ações, função muito além de bonecas enfeitadas.

Em 15 de novembro de 1902, no número 13, a revista apresentou na capa o título "Nossa Galeria". Nela destacaram-se algumas colaboradoras e pessoas ilustres da sociedade, entre as quais a foto de "D. Mafalda Mousinho de Albuquerque" ou "Modesta", poetisa e romancista portuguesa que era também colaboradora do jornal feminista brasileiro Escrínio, ${ }^{3}$ editado por Andradina América de Andrade e Oliveira. A proposta prorrogava-se para o segundo ano, quando apresentava capa e contracapa com o título "Revista D'arte". O novo formato passa a ser preenchido com 32 páginas de muitas ilustrações em preto e branco e, ao final da edição, uma publicação de folhetim. As fotografias das colaboradoras portuguesas e estrangeiras eram acompanhadas de pequenas biografias com textos laudatórios, poemas e excertos de livros, como é exemplo a edição n. 25 , de 1. ${ }^{\circ}$ de julho de 1903, que traz a escritora Maria Amália Vaz Carvalho, também colaboradora do Escrínio. Em 1. ${ }^{\circ}$ de maio de 1903, a Sociedade Futura anuncia que termina o ano de publicações e passa a sair mensalmente com um número de 16 páginas e "em ótimo papel”.

\footnotetext{
${ }^{3}$ Jornal feminino gaúcho publicado inicialmente na cidade de Bagé em 2 de janeiro de 1898. Posteriormente, teve publicações em Santa Maria, Rio Grande e Porto Alegre, cidade onde encerrou suas publicações em 25 de junho de 1910. Editado pela escritora, professora, dramaturga e contista gaúcha Andradina América de Andrada e Oliveira. O periódico mostrou-se como substrato na consolidação de uma rede de comunicação nas diversas relações estabelecidas entre as mulheres intelectuais no Brasil e fora do país.
} 
A Madrugada - lançada em 31 de agosto de 1911, substituía a revista A Mulher e a Criança, órgão oficial da Associação da Liga Republicana das Mulheres Portuguesas (LRMP), criada em 1908. A folha, que era mensal, tinha entre os nomes a tesoureira-diretora Maria Veleda ${ }^{4}$ e sua sócia Ana de Castro Osório.

As quatro páginas de $A$ Madrugada eram voltadas particularmente às questões feministas, sem falar na assiduidade dos relatórios de "Expediente da liga", onde constavam os gastos e movimentos do grupo, bem como o "balanço do mês" referente às despesas do jornal. Mas não faltavam publicações literárias, tanto de literatura nacional, quanto estrangeira. Da mesma forma, há um número fixo de seções que são distribuídas entre os seguintes títulos: "Ecos do estrangeiro", em que se publicam notícias sobre os movimentos feministas, manifestações e conquistas, em países como os Estados Unidos, Alemanha, África, entre outros. A seção de "Cartas" oriundas de diversos países, inclusive do Brasil, e apresentava exclusivamente a seção "Correio do Brasil", em 1912. Dela, constam as missivas enviadas por Ana de Castro Osório do Brasil, quando fixa residência em São Paulo acompanhando o esposo a exercer função de cônsul entre os anos de 1911 a 1914. No Brasil, ela estabelece vínculos com as intelectuais de vários estados num elo com o movimento feminista brasileiro.

Durante a permanência da feminista pelos trópicos, A Madrugada publicava as cartas que ela enviara para a redação, tendo como destinatária o nome de Maria Veleda. Todas as missivas são sempre muito longas, ocupando até três colunas do jornal. Seus conteúdos versam, por vezes, sobre a saudade de Portugal, as impressões do Brasil, viagens e "incentivos à propaganda que todas juntas começamos", como escreve Castro Osório em carta publicada em 31 de maio:

Minha cara Maria Veleda

Pede-me você que mande para A Madrugada, órgão atual da nossa Liga, algumas linhas sugestivas da minha impressão... de exílio. [...] escrevo na mesinha atulhada com os últimos jornais da semana, cheia de livros e de papeis. [...] E porque não ver a melancolia, a tristeza vaga e dolorida a que nós tão sentimentalmente chamamos de saudade, o grande fundo étnico deste grande povo, que mal irrompe agora a sua infância e já se impõe ao mundo caracteres definidos, com fisionomia própria [...] é certo que o Brasil foi uma obra admirável do gênio português. [...], mas, não foi para falar de paisagem [...] que pensei em escrever para A Madrugada, para o jornal onde nossas consócias poderão encontrar alguma indicação ou algum incentivo à propaganda que todas juntas começamos e da qual eu não desistirei. (ano I, n. 10, p. 1-2, 1912) .

\footnotetext{
${ }^{4}$ Educadora, "entre 1889 e 1905, Maria Veleda trabalhou como professora do ensino primário. [...] simultaneamente, desenvolveu grande atividade literária na imprensa regionalista, feminina e feminista. [...] Em 1902, publicou o opúsculo Emancipação feminina, que resume alguns textos publicados na imprensa. As ideias-chave do seu discurso feminista giram em torno da necessidade e urgência de as mulheres se empenharem na promoção da sua educação, a fim de se prepararem para o exercício de uma profissão digna. [...] Em 1909, "Maria Veleda foi julgada e condenada por abuso de liberdade de imprensa" (ESTEVES, 2008, p. 10), quando publica o artigo "Carta de uma dama franquista" (MONTEIRO, 2004)
} 
"Escrevo na mesinha atulhada com os últimos jornais da semana, cheia de livros e de papéis." Castro Osório canaliza esforços para não se afastar dos movimentos em Portugal e garantir a influência de suas opiniões: "nossas consorcias poderão encontrar alguma indicação ou algum incentivo à propaganda que todas juntas começamos e da qual eu não desistirei" ( ano I, n. 10, p. 1-2, 31 de mai. 1912).

Na seção "Cartas" A Madrugada publica em 31 de maio de 1913 o texto de Virginia de Castro e Almeida ${ }^{5}$ da Folha do Norte — da cidade de Belém, no Pará. O texto levanta um caloroso debate em torno do direito do voto para as mulheres:

Temos lutado muito e temos alcançado importantes vitórias. Em meados de cinquenta anos conseguimos para as mulheres uma instrução secundária e superior que faz honra à nossa terra; somos professoras ilustradas, médicas, diretoras de fábricas. Exercemos profissões liberais, ocupamo-nos na indústria e no comércio, defendemo-nos contra a injustiça da desigualdade dos salários por meio de um movimento sindical feminino perfeitamente organizado e que abrange mais de 60.000 mil membros, figuramos nas comissões da Assistência Pública que temos impulsionado de um modo maravilhoso, [...] temos livre disposição dos nossos salários, temos do casamento a separação de bens como regime legal, temos uma personalidade jurídica perfeitamente distinta do marido, no entanto há 500.000 mulheres proprietárias e contribuintes, há 5 milhões de mulheres que as condições da vida obrigam a ocupar-se de trabalho fora de casa, por amor de todas estas é absolutamente necessário e justo que a mulher alcance o direito de voto... que há de alcançá-lo, é uma questão de tempo (ano II, n. 22, p. 1).

No Brasil, os primeiros anos da Nova República foram de euforia para as feministas, que seguiam em crescente luta pelo progresso dos direitos na ordem política e civil, o que mostra o pequeno histórico do texto acima. Para tanto, foram os jornais o púlpito para a repercussão dessas querelas, pois reinava, ainda, "no Brasil, como em todo lugar, uma visão sentimental do lar e da mãe que era cara ao coração dos oradores antissufragistas" (HAHNER, 2003, p. 168).

O Brasil passava por mudanças importantes depois da proclamação de 1889. A primeira ação do governo provisório, que era chefiado pelo Marechal Deodoro da Fonseca, foi reunir um Congresso Constituinte para estabelecer discussões políticas que regularizariam as novas leis do país. O voto feminino tinha esteio em alguns congressistas; porém, argumentos que se pautavam na incapacidade intelectual feminina e o catecismo comtiano invocados por alguns, convenceram a grande maioria do congresso. Em razão disso, a primeira constituição republicana do país ignorou o direito de voto às mulheres, frustrando as expectativas das defensoras do sufrágio.

\footnotetext{
${ }^{5}$ Virginia de Castro foi ficcionista, tradutora e ensaísta portuguesa. Em 1907, a escritora lança Fada tentadora e Em pleno azul e Céu aberto, todas as publicações no mesmo ano. Tendo uma vasta produção literária, ela escreve até o ano de sua morte, em 1945, lançando Capital bendito: coisas que eu penso e Histórias de sua gente (FLORES, 2009).
} 
Frustradas, mas esperançosas, as feministas redobraram seus esforços em uma militância "efetiva" no primeiro decênio do século XX. Efetiva, porque ações concretas foram tomadas somente em um movimento organizado em 1910, quando a baiana professora e jornalista Leolinda de Figueiredo funda o Partido Feminino Republicano. Como a questão do sufrágio feminino não tinha mais sido discutida desde 1891, ela teria a missão de levar a discussão para dentro do Congresso. Das muitas questões a serem discutidas, o partido advogava em prol dos cargos públicos para mulheres, restritos aos homens.

A respeito do surgimento da imprensa exercida pelas mulheres no Brasil, tem-se, tradicionalmente o aparecimento do Jornal das Senhoras, ${ }^{6}$ que foi lançado em 1852 na cidade do Rio de Janeiro, pela argentina Joana Paula Manso de Noronha. Deve-se destacar que a redatora primava essencialmente pelas causas feministas, o que a levou a dirigir-se ao público masculino com o intento de conseguir apoio para suas campanhas pela igualdade de direitos.

No Rio Grande do Sul, a convivência entre as feministas era promovida pelo ambiente da imprensa que exercia um fundamental papel de divulgação das atividades literárias produzidas pelas mulheres. Aquelas que desejavam se fazer ouvir estabeleciam relações entre si, entre grupos letrados, entre imprensa, instituições e, por essas vias, formavam uma rede de apoio em busca da divulgação de suas obras e ideias.

Na cidade de Rio Grande, extremo sul do estado, Julieta de Melo Monteiro, aos 23 anos de idade, foi "proprietária e redatora" do jornal Violeta: periódico literário, crítico e instrutivo, publicado em 1878. O jornal variava muito suas publicações, mas geralmente saía aos domingos. Nele, a jovem jornalista acompanha os movimentos culturais, artísticos e literários, não só da cidade e região, como também dos grandes centros do país. Mas a redatora não tinha o objetivo só de propagar ilustração. Lê-se:

A mulher e seus direitos

A mulher que por meio dos estudos e das letras busca ilustração, a ciência, o douro pomo da sabedoria [...] e desterrando a ignorância é mais digna de louvores e de admiração que o homem [...] é errôneo pensar e até dizer que a mulher dada às letras falta aos deveres domésticos. [...] Deixem-nos, pois, hastear nosso estandarte. Soltarmos o grito não de rebelião, nem de revolta anarquistas, mas sim de apelo ao tempo de Minerva, à luta em prol dos nossos direitos. Revocata M. de Melo (VIOLETA, s.p.,1. ${ }^{\circ}$ de jun. 1879)

\footnotetext{
${ }^{6}$ Publicado no Rio de Janeiro, o jornal era impresso pela Tipografia Parisiense, na nova rua do Ouvidor, n. 20, e com o subtítulo "Modas, literatura, belas artes, teatro e crítica". Após seis meses de publicação, Noronha deixa a direção do jornal a cargo de Violante Atabalipa Ximenes e Veloso, que manteve a circulação do Jornal das Senhoras até 1853, quando transfere a direção para Gervásia Nunésia Pires dos Santos. O periódico, que circulava aos domingos, teve sua duração entre $1 .^{\circ}$ de janeiro de 1852 e 30 de dezembro de 1855 (BERNARDES, 1988).
} 
A temática sobre a igualdade de direitos para as mulheres foi também uma constante em outro jornal fundado posteriormente por Julieta em conjunto com a irmã Revocada Heloisa de Melo, o Corymbo. ${ }^{7}$ O jornal, que circulou entre 1883 a 1945 com alguns poucos intervalos (VIEIRA, 1997), merece relevância na história da imprensa e, quiçá, da imprensa feminina mundial se for considerada a efemeridade da publicação de periódicos no Brasil (SODRÉ, 1966) e, sobretudo, de periódicos femininos.

O Corymbo recebia diversas colaborações originadas de vários estados do Brasil e do exterior. Em algumas edições analisadas, os assuntos versam sobre educação, o voto, a profissionalização feminina e o divórcio. Nesta última temática fica evidente que o jornal legitima seu direito e seu dever de divulgar e publicar fatos de interesse público, conforme segue:

Divórcio

À convite do ilustre e estimável vigário desta paróquia reuniu-se na Igreja Matriz, domingo passado, um grande número de senhoras com o fim de assinarem um protesto dirigido ao Senado Federal contra o projeto da Lei do divórcio absoluto! Neste mesmo dia foram dirigidos telegramas ao Presidente do Senado, Presidente da Câmara dos Deputados e Senadores Dr. Ramiro Barcellos e Padre Alberto Gonçalves, [...], assinados pelas distintas e simpáticas Exmas. Sras. Baronesa de Santa Martha, Maria Luiza Viana e Mara Pinto Chaves, dignas conterrâneas comissionadas pelas senhoras rio-grandenses, para representá-las na referida causa. (CORYMBO, ano XIII, n. 21, p. 2, 26 de jul. 1896)

$\mathrm{O}$ assunto em pauta referia-se ao projeto de lei sobre as mudanças na legislação matrimonial, como legitimar o "divórcio absoluto". Por conta dessas mudanças, a sociedade conservadora apoiada pela "igreja a reger e regrar todos os aspectos do viver humano" (QUEIROZ, 2014, p. 24), ergue-se em protestos e ações das "distintas e simpáticas senhoras" (Escrínio, , Rio Grande/ Bagé, ano I , [s.p], 2 de jan. 1898).

Impresso em quatro páginas, à primeira vista o jornal apresenta seções como "Folhetins", "Seção poética", "Charadas", "Noticiário", noções sobre puericultura e, em última página, um espaço publicitário. Andradina tinha intenção de transformar seu periódico em ferramenta de promoção e valorização das mulheres, conforme se lê:

Fundado por uma filha desta encantadora terra, por fervorosa defensora do seu sexo, o Escrínio surge, também como um incitamento à mulher rio-grandense, convidando-a a romper o denso casulo da obscuridade, e vir à tona do jornalismo trazer as pérolas da sua cultivada inteligência! (ESCRÍNIO, ano I, n. I, p.1, 2 de jan. 1898).

\footnotetext{
${ }^{7}$ Ver o estudo sobre o periódico em Vieira (1997) e Póvoas (2005).
} 
Por acreditar no progresso feminino a partir da educação e do trabalho e utilizar o jornal como ferramenta para alcançar esse objetivo, Andradina contava com um número de colaboradoras que apoiavam e militavam pela causa, como Julia Lopes de Almeida, de São Paulo, Francisca Clotilde, do Ceará, Maria Clara da Cunha Santos e Madame Chrysanthéme, ambas do Rio de Janeiro, Delminda Silveira, de Santa Catarina e, ainda, a educadora Mariana Coelho e a cronista Cândida Brandão. Muitas delas eram também jornalistas. Tornava-se visível, nesse âmbito, a recíproca troca que se estabelecia entre os próprios periódicos.

Todavia, não faltaram também os encontros pessoais. Depois de retornar para Portugal, Ana de Castro Osório voltou algumas vezes para o Brasil, pois afirmava que "era necessário que viesse, e vim, para continuar a obra de simpatia e de ligação moral, que tem sido o sonho da minha vida!" (OSÓRIO, [s.d.], p. 16). Em 1923, ela visita o estado do Rio Grande do Sul onde, na cidade do Rio Grande, encontra-se com as irmãs Revocata e Julieta.

Amigas de longa data, integrava-se ao grupo a conterrânea portuguesa Maria Amália Vaz de Carvalho. Todas elas eram assíduas colaboradoras do Corymbo. Amália também era colaboradora do Escrínio, enquanto as rio-grandinas eram presença certa nas páginas de $A$ Madrugada, segundo notícia do próprio Corymbo, que publica um texto de Revocata "cujo retrato em miniatura fulge na primeira página da Madrugada" (CORYMBO, apud VIEIRA, 1997, p. 67) — isso ainda em 1896. Para Castro Osório, "tanto em Portugal, como no Brasil, a mulher afirma-se em nomes tão gloriosos que o citá-los em detalhe seria tarefa para querer largo tempo e muita erudição" (OSÓRIO, [s.d.], p. 17).

Baseada nos estudos de gênero à luz das ciências sociais, a imprensa feminina é uma fonte de estudo não para dar vida às pessoas relegadas ao papel, mas para compor uma história do processo de construção da identidade feminina. Nesta, acreditamos que o Atlântico foi um caminho rumo à ordem das relações humanas, ordem moderada pelos jornais. Os movimentos feministas se somaram entre o Brasil e Portugal. As mulheres estavam presentes nas redações e nas associações de forma a promover a consciência política em favor da democracia em ambos os países.

As campanhas que as mulheres realizaram outrora nunca se tornaram movimento de massa, mas a persistência e o consenso sobre o que é "ser mulher" reverberou uma visão universalista numa história que ainda hoje é construída por todas.

\section{Referências}

A MADRUGADA, Lisboa, ano I, n. I, 31 de ago. 1911

A MADRUGADA, Lisboa, ano I, n. 10, p. 1-2, 31 de mai. 1912.

A MADRUGADA, Lisboa, ano II, n. 18, 31 de jan. 1913.

A MADRUGADA, Lisboa, ano II, n. 22, p. 1, 31 de mai. 1913. 
A VOZ FEMININA, Lisboa, ano I, p. 1-2, n. 1, 5 de jan. 1868.

CORYMBO, Rio Grande, ano XIII, n. 21, p. 2, 26 jul. 1896.

ESCRÍNIO, Hebdomadário Litterário, Insctructivo e Noticioso, Rio Grande/Bagé, ano I, [s.p.], n. 1, 2 de jan. 1898 .

ESCRÍNIO, Hebdomadário Litterário, Instructivo e Noticioso, Rio Grande/Bage, ano I, n. I, p, 1, 2 de jan. 1898.

ESTEVES, João. Mulheres e republicanismo (1908-1928). Lisboa: Comissão para a Cidadania e Igualdade de Gênero. [s. ed.] 2008. (Coleção Fio de Ariana, v. 5).

FLORES, Conceição; CONSTÂNCIA, Duarte L; MOREIRA, Zenóbia C. Dicionário de escritoras portuguesas: das origens à atualidade. Florianópolis: Mulheres, 2009a.

FLORES, Hilda Agnes Hubner. Lola de Oliveira. In: MUZART, Zahidé Lupinacci (org.). Escritoras brasileiras do século XIX. Florianópolis: Mulheres, 2009b. p. 705-736.

HAHNER, June Edith. Emancipação do sexo feminino: a luta pelos direitos da mulher no Brasil (1850-1940). Florianópolis: Mulheres; Santa Cruz do Sul: EDUNISC, 2003.

LOUSADA, Isabel. Adelaide Cabete (1867-1935). Lisboa: Comissão para a Cidadania e a Igualdade de Gênero-Presidência do Conselho de Ministros, 2010. (Coleção Fio de Ariana, v. 6). MONTEIRO, Natividade. Maria Veleda (1871-1955). Lisboa: Comissão para Igualdade dos Direitos das Mulheres, 2004. (Coleção Fio de Ariana, v. 1).

OSÓRIO, Ana de Castro. A grande aliança. In: VALE, Fernando (org.). Lisboa: Instituto Piaget, [s.d.].

PÓVOAS, Mauro Nicola. Uma história da literatura: periódicos, memória e sistema literário no Rio Grande do Sul do século XIX. 2005. Tese (Doutorado em Letras) - Pontifícia Universidade Católica do Rio Grande do Sul, Porto Alegre, 2005.

QUEIROZ, Júlio. A mulher na humanidade. In: FERRAZ, Salma (org.). Florianópolis: FAPESC; Blumenau: EdiFurb, 2014.

RODRIGUES, Ernesto. Mágico folhetim: literatura e jornalismo em Portugal. Lisboa: Notícias, 1998.

SOCIEDADE FUTURA: Revista quinzenal de educação, literatura e ciência, Lisboa, ano I, n.

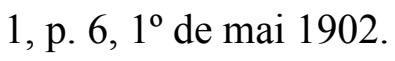

SODRÉ, Nelson Werneck. História da imprensa no Brasil. Rio de Janeiro: Civilização Brasileira, 1966.

VIEIRA, Míriam Steffen. Atuação literária de escritoras no Rio Grande do Sul: um estudo do periódico Corymbo, 1885-1925. 165p. Dissertação (Mestrado em Ciências Sociais). Universidade Federal do Rio Grande do Sul, Porto Alegre, 1997.

VIOLETA. Periódico Literário Crítico e Instructivo. Typografia da Violeta. Rio Grande do Sul, ano I, n. 3, 31 de mar. 1878.

VIOLETA. Periódico Literário Crítico e Instructivo. Typografia da Violeta. Rio Grande do Sul, ano II, n. 43, 6 de abr. 1879. 
VIOLETA. Periódico Literário Crítico e Instructivo. Typografia da Violeta. Rio Grande do Sul, ano II, n. 44, 13 de abr. 1879.

VIOLETA. Periódico Literário Crítico e Instructivo. Typografia da Violeta. Rio Grande do Sul, ano II, n. 50, [s.p.], 1 jun. 1879.

\section{Minicurrículos}

Paula Renata Lucas Collares Ramis é licenciada em Letras pela Universidade Federal de Pelotas; mestre em Letras, em História da Literatura pela Universidade Federal do Rio Grande (Furg); doutora em Letras pela Pontifícia Universidade Católica do Rio Grande do Sul

Rosa Cristina Hood Gautério é graduada em Letras pela Furg; mestre em Letras pela mesma universidade, sob a linha de pesquisa "Literatura, história e memória Literária"; doutora em Literatura pela Universidade Federal de Santa Catarina; com estágio de doutorado na Faculdade de Letras da Universidade de Lisboa, Portugal, vinculada ao Centro de Literatura e Culturas Lusófonas e Europeias (Clepul). 